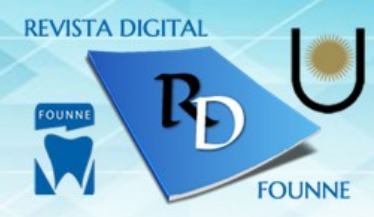

\title{
Evaluación del estado de Salud Bucal de niños en 4 y 5 años que asisten al Centro de Desarrollo Infantil Mitai Roga $N^{\circ} \mathrm{V}$, de la ciudad de Corrientes Capital.
}

\section{Autores:}

*Dra. Beatriz Juana Cardozo -** Dra. Gabriela Bessone -***Esp. Silvia Rita Pérez - ****Esp. Patricia Alejandra Vaculik- *****Esp. Elena Griselda Sanz

Autor de correspondencia: malusacardozo2@hotmail.com Av. Libertad 5450. CP 3400. Facultad de Odontología, Universidad Nacional del Nordeste. Corrientes, Argentina.

Recepción: 05 de mayo de 2017

Aceptación: 05 de junio de 2017

\section{Resumen:}

La caries en la infancia temprana es una forma particularmente virulenta de caries que afecta a los niños más pequeños y que puede causar grandes estragos en la dentición de los infantes en un periodo particularmente corto. Esta enfermedad representa un importante problema de salud pública en muchos países del mundo, ya que su prevalencia ha alcanzado proporciones epidémicas entre niños pertenecientes a países en vía de desarrollo. Se realizó un estudio descriptivo, longitudinal en niños entre 4 y 5 años de ambos sexos, que asistieron al Centro de Desarrollo Infantil Mitai Roga $\mathrm{N}^{\circ} \mathrm{V}$ de la ciudad de Corrientes durante el año 2016. El objetivo fue evaluar el estado de Salud Bucal en niños de 4 y 5 años que asistieron al Centro de Desarrollo Infantil Mitai Roga $\mathrm{N}^{\circ}$ V. Se realizaron registros en la Historia Médica-Dental, examen clínico, previo consentimiento Informado. Posteriormente se llevó a cabo el Programa "Por una sonrisa sana y feliz". Los registros obtenidos reflejan que el 65\% de los niños presentan caries, por lo cual es necesaria la implementación de programas de promoción y prevención de la salud bucal, la modificación de hábitos de vida para mantener y preservar la salud.

Palabras claves: educación - preescolar - hábitos

* Profesora Titular - Módulo Introducción a la Práctica Clínica. mail: ** Profesora Adjunta Módulo Morfofunción I-***_ Prof. Adjunta - Módulo Introducción a la Práctica Clínica -**** - 


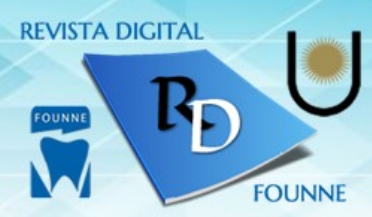

Prof. Adjunta Odontología Integral Práctica Profesional Supervisada (PPS)***** Auxiliar Docente - Módulo Introducción a la Práctica Clínica.

\section{Introducción}

La Organización Mundial de la Salud (O.M.S) en el año 2000, propuso que la promoción de la Salud bucodental debe ser prioritaria en las poblaciones de niños preescolares y escolares. Con ello, se pretende minimizar el impacto de las enfermedades de origen bucodental y cráneo-facial sobre la salud general y sobre el desarrollo psicosocial, dando mayor énfasis a las poblaciones que se ven más afectadas por esas condiciones y enfermedades. ${ }^{(1)}$

La caries dental es considerada como el evento de mayor peso en la historia de la morbilidad bucal a nivel mundial. ${ }^{(2)}$

Estas son causadas por la presencia de una biopelícula producto de la organización estructural de diferentes tipos bacterianos dentro de un hábitat propicio, facilitado por la deficiente higiene bucal, que por sus mecanismos patológicos y los múltiples factores involucrados afectan a todos los individuos. ${ }^{(3)}$

Numerosos estudios revelan que la caries dental es la enfermedad que padece aproximadamente 90\% de la población en América Latina; lo más alarmante es que comienza en la etapa temprana de la vida y se incrementa a medida que el individuo crece. ${ }^{(4)}$

La caries de infancia temprana es una forma particularmente virulenta de caries que afecta a los niños más pequeños y que puede causar grandes estragos en la dentición de los infantes en un periodo particularmente corto. La enfermedad puede seguir patrones característicos a los pocos meses de su erupción, y los primeros dientes afectados son los incisivos superiores. Las lesiones cariosas aparecen rápidamente en los dientes y siguen la secuencia de erupción. Se ha determinado una clara relación entre los hábitos alimenticios inadecuados y la salud oral. ${ }^{(5)}$

Esta enfermedad representa un importante problema de salud pública en muchos países del mundo, ya que su prevalencia ha alcanzado proporciones epidémicas entre niños pertenecientes a países en vía de desarrollo, en los que las condiciones de desnutrición son comunes; pero también en las poblaciones de bajos recursos económicos en los países desarrollados. ${ }^{(6)}$ 


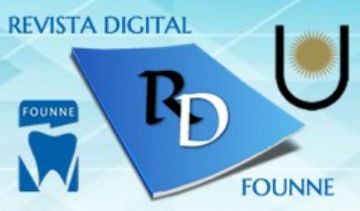

La caries dental en niños preescolares se debe a una combinación de múltiples factores, incluyendo la colonización de los dientes con las bacterias cariogénicas, el tipo de alimentos consumidos así como la frecuencia de la exposición de estos alimentos para las bacterias cariogénicas, y los dientes sensibles. ${ }^{(7)}$

La prevención en salud oral son aquellas actividades que buscan controlar los factores de riesgo causantes de las diferentes patologías orales. Tiene un elemento común, que es el control de la placa bacteriana, mediante una adecuada higiene oral, teniendo en cuenta que la supresión de la actividad microbiana ha demostrado ser eficaz en la prevención del desarrollo de lesiones cariosas y pérdida de inserción periodontal. ${ }^{(8)}$

El cepillado dental ha sido, por muchos años, el principal mensaje de educación dado a niños, adolescentes y adultos, se basa la supuesta ayuda a eliminar la placa y facilita el contacto íntimo del fluoruro contenido en la pasta dental con los dientes. Para promover eficazmente el cepillado dental es necesario entender los factores asociados con esta práctica/conducta de higiene. ${ }^{(9)}$

En la formación de hábitos adecuados de higiene oral, la promoción de la salud oral y la prevención de la enfermedad juegan un papel preponderante y se consideran acciones fundamentales para el control de la placa bacteriana. ${ }^{(8)}$

Los objetivos de este estudio fueron 1- evaluar el estado de Salud Bucal en niños de 4 y 5 años que asisten al Centro de Desarrollo Infantil Mitai Roga $\mathrm{N}^{\circ} \mathrm{V}$ de la ciudad de Corrientes Capital. 2- Implementar un programa de educación y prevención de la salud y evaluar.

\section{Materiales y métodos:}

Se realizó un estudio descriptivo, de corte longitudinal, en niños de 4 y 5 años de edad, en ambos sexos durante el año 2016. La investigación se realizó en tres etapas, la primera denominada Diagnóstico Inicial donde se llevó a cabo la recolección de los datos, la segunda en la cual se ejecutó el Programa por Una Sonrisa Sana y Feliz y la tercera donde se evaluó el Impacto mediante el diagnóstico final. En la primera etapa previa autorización de los tutores se confeccionaron las historias clínicas, odontograma consignando el estado actual de las piezas dentarias. Para cuantificar se utilizó el índice ceod para dentición primaria y el índice de O'Leary para evaluar la calidad de higiene oral del niño. En la segunda etapa se ejecutó el Programa por Una Sonrisa Sana y Feliz que se llevó a cabo en dos módulos. El Módulo Educativo y el Módulo 


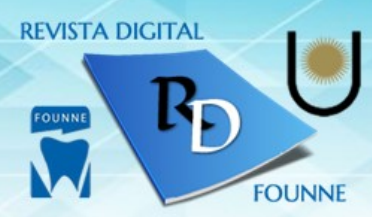

\section{Artículo de Opinión}

de Atención Preventiva. En la tercera etapa se realizaron los controles del Índice ceod y O'Leary, a fin de evaluar el impacto del programa educativo y preventivo aplicado.

\section{Resultados:}

Se hallaron al examen clínico un total de 98 piezas dentarias cariadas, 3 extracción indicada y 2 piezas dentarias obturadas, luego se aplicó el Programa y se observó como disminuyó el número de piezas dentarias cariadas a 24 , extracción indicada a 0 y aumentó notablemente el número de piezas dentarias obturadas a 75 . (Figura $\mathrm{N}^{\circ} 1$ )

El promedio total de dientes cariados, perdidos y obturados (c.e.o.d) antes de aplicar el Programa fue de 2.7 y posterior a la aplicación del Programa fue de 2.5. (Figura $\mathrm{N}^{\circ} 2$ ).

El porcentaje de niños que presentaron valores del índice de O’Leary no compatibles con salud fue el $84 \%$ que corresponde a 32 niños y el $15 \%$ que corresponde a 6 niños los que presentaron valores compatibles con salud antes de implementar el Programa. (Figura $\mathrm{N}^{\circ} 3$ ).

Luego de la aplicación del programa el porcentaje de niños que presentaron valores del índice de O'Leary compatibles con salud fue el $74 \%$ que corresponde a 28 niños y valores no compatibles con salud el $26 \%$ que corresponde a 10 niños (Figura $\mathrm{N}^{\circ} 4$ ).

Figura $\mathbf{N}^{\circ} 1$ Número de piezas dentarias cariadas, extracción indicada y obturados c.e.o.d.

Inicial y posterior a la aplicación del Programa

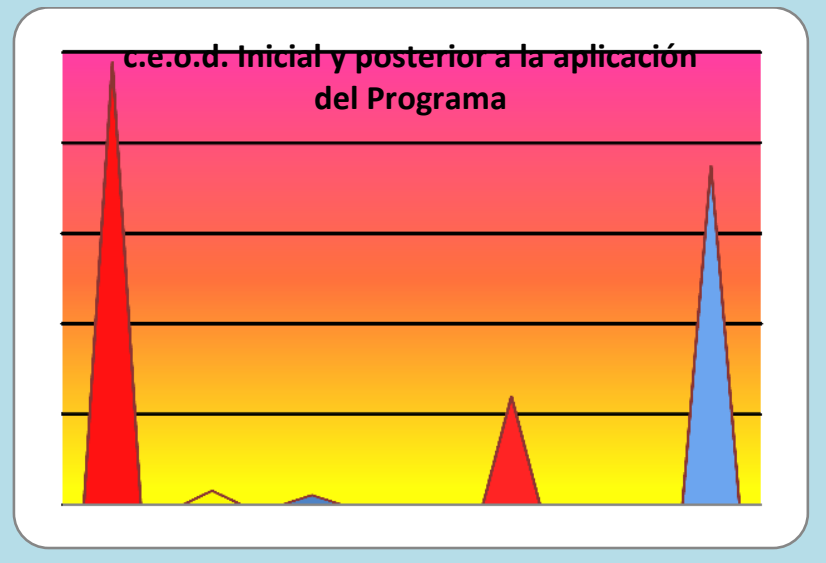

Figura $\mathbf{N}^{\circ} 2$ Promedio c.e.o.d total anterior y posterior a la aplicación del Programa 


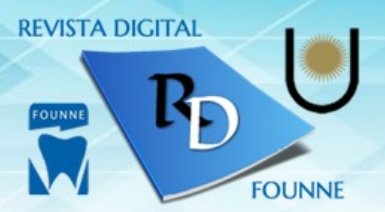

\section{Artículo de Opinión}

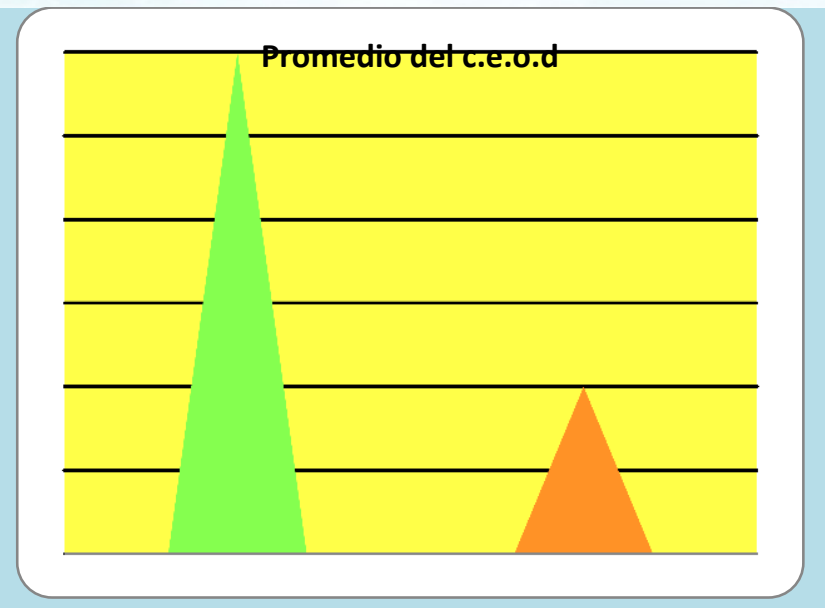

Figura $\mathbf{N}^{\circ} 3$ Índice de O’Leary anterior a la implementación del Programa

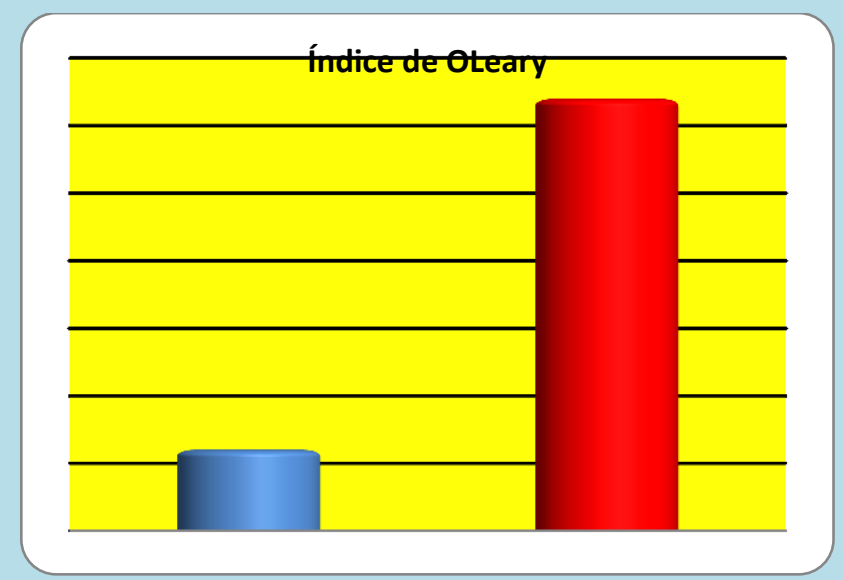

Figura $N^{\circ} 4$ Índice de O’Leary posterior a la implementación del Programa

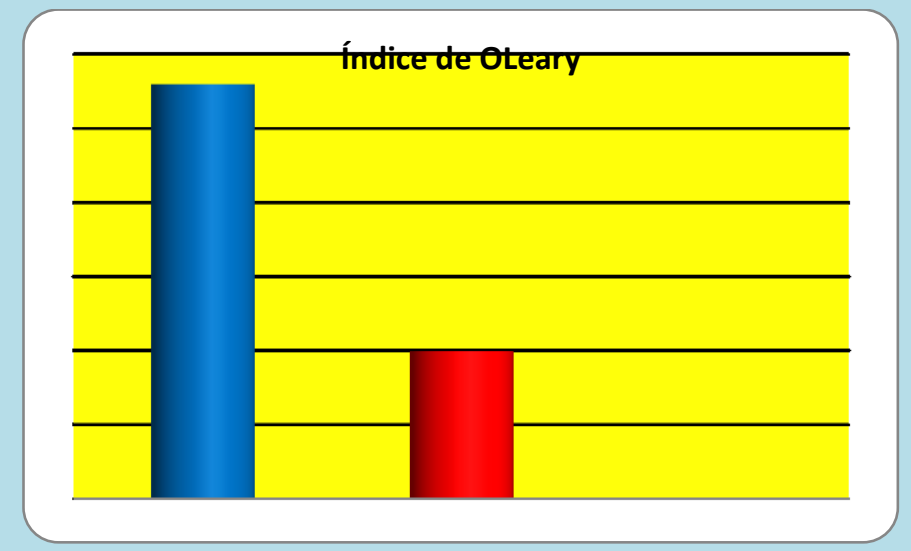




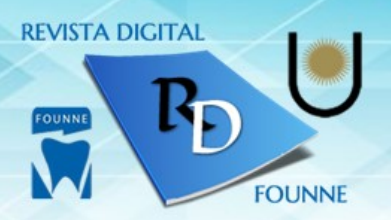

\section{Discusión:}

Los resultados obtenidos en éste trabajo reflejan que el 65\% de los niños presentan caries dental, lo que tiene sus repercusiones en el área odontológica, porque todos somos conscientes de la alta prevalencia de las dos enfermedades más comunes de la cavidad bucal, caries y enfermedad gingival.

Numerosos estudios han demostrado que el biofilm dental es el responsable principal de las dos patologías más frecuentes en la cavidad bucal.

Los resultados hallados en éste estudio coinciden con otros estudios epidemiológicos realizados por la Mgter. Prof. Cardozo, Beatríz y colaboradores en alumnos de la Escuela Familia Agrícola en San Miguel, Corrientes donde el $97,2 \%$ de los escolares presenta caries dental, el 55\% corresponde al sexo masculino y el $37,5 \%$ al sexo femenino. ${ }^{(10)}$

Olmedo Sánchez y colaboradores revela en un estudio realizado que el $85.4 \%$ del total de la población escolar presenta piezas dentarias cariadas y que el mayor el porcentaje de dientes afectados por las caries se encuentra en el sexo masculino. ${ }^{(11)}$

En éste estudio se ha evidenciado la disminución de los valores del índice de O'Leary del 1er control con respecto al 2 do, luego de la enseñanza de una correcta técnica de cepillado. Estos resultados coinciden con estudios realizados por García Crimi donde los valores de los índices de placa bacteriana disminuyeron del 1er control con respecto al 2do, se pudo observar la buena evolución que tuvieron con respecto al control de placa bacteriana y la incorporación de una correcta técnica de cepillado siendo esto fundamental para evitar la aparición de nuevas lesiones de caries. ${ }^{(12)}$

Se ha hallado coincidencia con otros estudios sobre la incidencia y prevalencia de caries que demostraron que la aplicación de numerosas medidas preventivas disminuyeron considerablemente los índices ceod y CPOD en un 30 a 50\%, cuando se implementaron programas preventivos y/o de atención de escolares.

En América Latina se han desarrollado diferentes programas preventivos: tal es el caso de Panamá, con "Sonríe Latinoamérica" (13), Cuba con "Sonrisas Saludables" (14) y Perú con la "Clínica del Bebe"(15) 


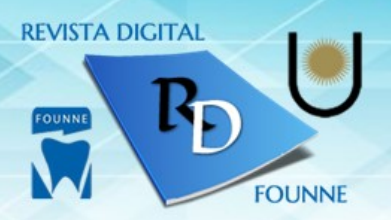

\section{Conclusión:}

El programa de educación para la salud buco-dental resaltó la importancia de la prevención en la salud bucal, estimuló el interés de los maestros y niños para la enseñanza y aprendizaje sobre el cuidado de la cavidad bucal.

En base a los resultados obtenidos se observó que la aplicación del Programa ha evidenciado la disminución de los valores del índice de O’Leary del 1er control con respecto al 2do, luego de la enseñanza de una correcta técnica de cepillado y cambios importantes en la adquisición de nuevos hábitos de higiene bucal en los niños que participaron en él.

\section{Bibliografía:}

1. OMS. Vigilancia y evaluación de la Salud Bucodental. Informe de un Comité de Expertos. En: Serie de Informe Técnicos. Ginebra: 1989: 29-30

2. Petersen PE. The world oral health report 2003: continuous improvement of oral health in the 21 st century-the approach of the WHO Global Oral Health Programme. Community Dent Oral Epidemiol. 2003;31(1):3-23.

3. Pérez A. La Biopelícula: Una nueva visión de la placa dental. Rev Estomatol Herediana. 2005;5(1):82-5.

4. Argentina, Ministerio de Salud, Secretaría de Ambiente y Desarrollo Sustentable; Programa de Naciones Unidas para el Medio Ambiente. Argentina 2006: Indicadores ambientales. Iniciativa latinoamericana y caribeña para el desarrollo sostenible. Indicadores de seguimiento. Buenos Aires; 2006.

5. González GE. Jardín infantil de la Universidad Nacional de Colombia: evaluación de un programa para la promoción de salud oral en la primera infancia. Univ Odontol. 2012 EneJun; 31(66): 59-74

6. Gudiño FS. Caries de la temprana infancia: denominación, definición de caso y prevalencia en algunos países del mundo. Revista Odovtos [internet]. 2006

7. González Sanz Ángel Miguel, González Nieto Blanca Aurora, González Nieto Esther. Salud dental: relación entre la caries dental y el consumo de alimentos. Nutr. Hosp. vol.28 supl.4 Madrid jul. 2013. ISSN 1699-5198

8. UNICOC. Guía Práctica Clínica en Salud Oral. Bogotá D.C., 2010; 4.

9. Medina SCE,Segovia VA,Rodriguez RE. Asociación del nivel socioeconómico con la higiene bucal en preescolares bajo el programa de odontología preventiva del IMSS en Campeche.Gac Méd Méx 2006;142(5):134-45.

10. Cardozo B, Gonzalez Meana M, Tropeano N. Estudio Epidemiológico Estado de Salud dental en alumnos. Escuela Familia Agrícola- San Miguel- Ctes. Revista Facultad de Odontología FOUNNE; 16-18, 2006.

11. Olmedo Sánchez A; Solorzano Villaseñor B; González Gaytan I; Díaz García B; Pérez Santana R. Prevalencia de caries en escolares de Pueblo nuevo, Santa Catarina 
Cuexcomatitlan, Mezquitic, Jalisco. Revista Odontológica Mexicana 2008; 12 (S1): S10S42. ISSN 1870-199X.

12. García Crimi, G. Promoción de Salud Bucodental en establecimientos educativos del Valle de Uco de la Provincia de Mendoza. Facultad de Odontología UNCuyo. 2010. Volumen 4. $\mathrm{N}^{\circ} 1$.

13. Evans, J. Sonríe Latinoamérica. Panamá. 2001

14. Diaz Del Mazo, 1. Sonrisas Saludables para capacitar adolescentes sobre Salud Bucal. Cuba. Medisan; 2003

15. Elias, M. Programa Clínicas del Bebè. Perú. 2001

16. Barrancos Mooney, J. Operatorias Dental Integración Clínica. $4^{\mathrm{a}}$ ed. Buenos Aires Argentina: Editorial Médica Panamericana; 2008.

17. Cid María del Carmen, Martínez I, Morales JM. Ingestión de azúcares en niños menores de 1 año. Revista Médica Electrónica. 28 (1):113-6; 2008. 